\title{
Conceptual Model of Aircraft “Chiroptera”
}

\author{
Iftikhar B. Abbasov* \\ Taganrog Technological Institute of the Southern Federal University, per. Nekrasovskyi, Taganrog, Russia \\ *Corresponding author: iftikhar_abbasov@mail.ru
}

Received March 09, 2014; Revised March 24, 2014; Accepted April 03, 2014

\begin{abstract}
The paper is concerned with conceptual modeling of the new aircraft based on bionical forms. Search visual-graphic calculations of the model under development are presented. 3D modeling of aircraft constructional parts were carried out according to the detailed designs. For 3D surfaces modeling the Koons method is used. Rendering scenes of shaded 3D model of aircraft is presented.
\end{abstract}

Keywords: conceptual model, bionics, chiropters flight, Koons surface, aircraft 3D model, shading and rendering

Cite This Article: Iftikhar B. Abbasov, “Conceptual Model of Aircraft “Chiroptera”.” American Journal of Mechanical Engineering, vol. 2, no. 2 (2014): 47-49. doi: 10.12691/ajme-2-2-3.

\section{Introduction}

Issues of aircraft state of the art technologies of computer modeling and design application are actual. Let's consider some of the modern literature references in this sphere. The article [1] is concerned with conceptual design of passenger tailless airplane. Different aerodynamic configurations are presented and analyzed.

The article [2] is concerned with aircraft conceptual design where birds wing aerodynamic properties are taken into account. In papers $[3,4]$ the design of economical-to operate passenger aircraft issues are considered.

In paper [5] the conceptual design properties of new generation supersonic aircraft with original arrangement of landing gears and fuel tank are given.

The article [6] describes specific features of modern software tools implementation for design objectives. New software possibilities of aircraft structure development are described.

This paper is concerned with 3D computer modeling of new aircraft concept. For aircraft modeling the Koons surfaces method (or Edge Mesh) is used. This method enables to create curvilinear streamlined surfaces based on four closed arbitrary 3D splines. Based on analysis of air environment natural forms renfering imagery, the aerodynamic characteristics of the only flying mammals chiroptera seemed to be attractive. Skin stretched between their fingers looks like Koons surfaces built per Edge Mesh.

\section{Concept of Modelling}

Wing-handed animals (Chiroptera) - from Greek

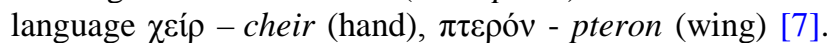
Chiroptera is the only placental mammals able for active flight. They are divided into two suborders: fruit bats and bats. They are widely spread geographically (except tundra and polar regions). Their main way of travel is a flapping flight. It enables to use biological resources inaccessible for other mammals. In general, chiroptera feeds insects, small vertebrata, fish and fruits as well. They are active in evening shades and nights, in daylight time they hide in different shelters. That's why in many cultures chiroptera, especially bats, have a bad repute and associated with evil magic and witchcraft.

Speed of their flight depends on wing shape [8]. Relatively high speeds are typical for lunkers who have long arrow-headed wings. Flapping flight for chiropteras is typical but some representatives use hovering and gliding flight. In flight at high speeds the birds can change their wings length and square and chiropteras can't bend wing without all membrane releasing. However in contrast with birds they can freely change wing profile outline.

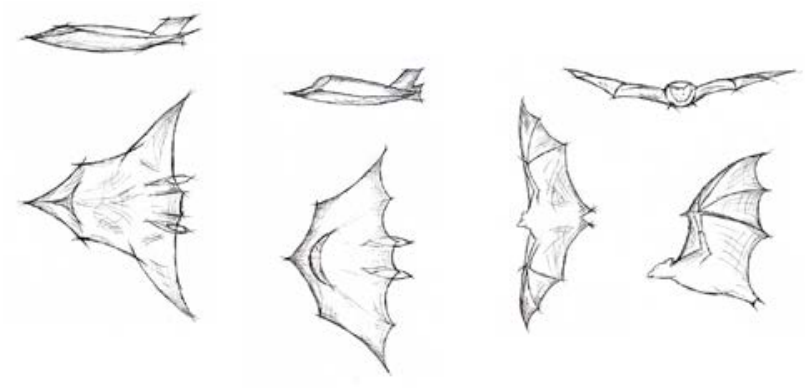

Figure 1. Variant of creative search

In the history of world aviation the first attempts to create aircraft were connected with birds flight imitation. The first time the aircraft with a wing like bat's was created by French engineer Clement Ader (Clément Ader, 1841-1925) [9]. His aerostatic machine was a tailless monoplane without vertical fin. Fuselage and wing frames were manufactured of bamboo silk-fabric covered. Aircraft was equipped with two pusher propellers with four blades each of which was fitted with steam engine. He called his aircraft "Eole" in honor of ancient Greek Olympian Eolus. In October, 1890 C. Ader tried to fly on "Eole" which took off and flew about $50 \mathrm{~m}$. However, 
because of lateral controls absence he failed to perform full flight. But it was the first self-moving flight in the history carried out 13 years prior brothers Wright's flight.

Aircraft conceptual development starts from creative search stage: choice of style, composite approach, sketch creation, future model draw [10,11]. On Figure 1 the sketches of natural bionic forms and variants of creative search are shown. High speed aircraft id assumed to be modeled and therefore as a final variant the construction with extended arrow-headed wing was chosen (Figure 1, left side).

Further the chosen sketch is modified based on aerodynamic, operating characteristics and ergonomic requirements. After that the stage of $3 \mathrm{D}$ modeling based on detailed design takes place. In this work graphic modeling system AutoCAD will be used. Nowadays there is a fair number of $3 \mathrm{D}$ modeling graphic systems and CAD system. Graphic system AutoCAD enables not only to create and correct drawings, as well it can carry out 3D surface, solid modeling and create realistic rendering. It should be noted that the author has considered the issues of amphibian aircraft 3D computer modeling in his papers $[12,13]$. In the paper [12] the issues of amphibian aircraft conceptual design based on bionic forms were described.

\section{Modelling Method}

To apply Koons method it is necessary to build overall 3D box [14]. 3D box is constructed by means of rectangle extrusion to some height. On each side edge of $3 \mathrm{D}$ box the curvelinear spline per closed loop is constructed (Figure 2, right side, below). With the help of command Edge Mesh the constructed splines are pointed step by step resulted in smoothed curved surface.

While creating aircraft it is necessary to analyze the commands of surface modeling available as well as possibilities to design components of the object under modeling. We decompose aircraft (based on airframe axis): airframe upper and lower surface, vertical fin surface and engine surface. For better aerodynamic properties the aircraft airframe should be streamlined and for its creation the method of Edge Mesh will be used. Tail unit and engine nozzles can be created with command Ruled Mesh.

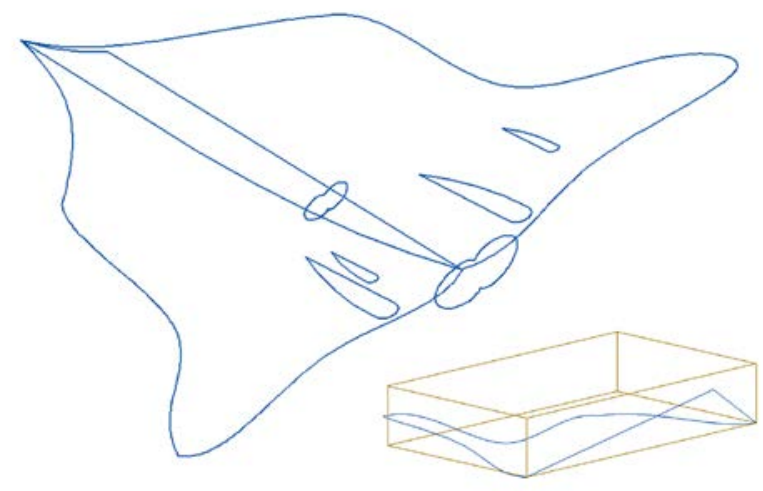

Figure 2. Original plane forms of aircraft surface

With the help of 3D box the half of stream-lined body along its axis is created. To create triangle outline of the body upper part it is necessary to shift one of the closed spline peaks inside 3D box. Using Mirror tool the wing splines mirrored copies are constructed. Original flatness for tail unit and nozzle is constructed in the form of polylines and a spline. The result of preparatory work to create aircraft surface in the form of flat splines and polylines is shown on Figure 2.

Prior performing 3D modeling let's consider design features of the aircraft model under development. Aircraft aerodynamic configuration pertains to "flying wing" type (without fuselage). As for arrangement it is a monoplane, wing geometry in plan view is a variety of delta wing “ogival” type $[15,16]$. Nowadays monoplane configuration with wing different arrangement is usually used. Delta wing is used mostly for supersonic aircraft. In comparison with straight wings they have a drag at cruise mode and enable to use wing inner volumes more effectively. Aircraft has no horizontal tail (tailless), vertical tail is a twin-finned one. Power plant consists of two turbojet engines located in vertical stabilizer section of the body. Landing gear configuration is supposed to be tricycle nose wheel landing gear.

In order to create aircraft 3D surface the body's left and right parts are generated step by step with the help of Edge Mesh command. With the help of command Ruled Mesh the tail part and engines nozzles are created. The result of generation in three orthogonal and isometric projections are presented in Figure 3. If necessary the body's original plane figures can be corrected for aircraft aerodynamic characteristics.

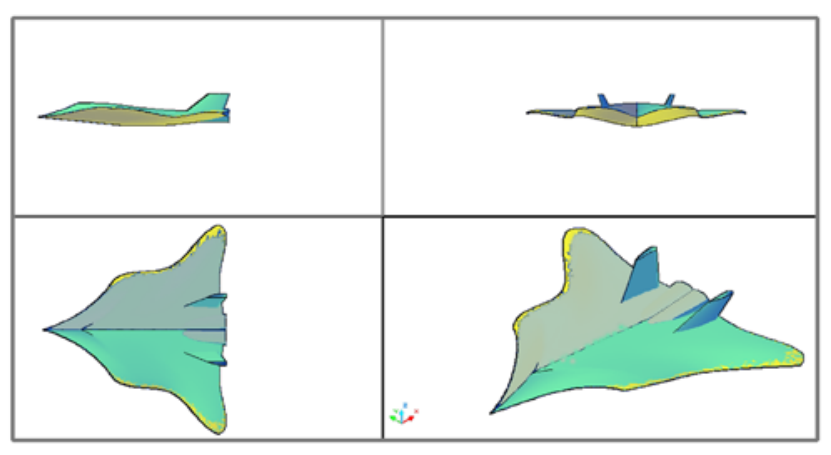

Figure 3. 3D surface model of aircraft in projections

\section{Rendering of 3D Model}

Further, in order to create accurate rendering scene it is necessary to assign the materials and determine lighting. The work with materials consists of two stages: adding (creating) new materials to drawing and material binding to scene objects. Creation of appropriate materials is an important part of shading process because the final result considerably depends on this. The material, in its turn, interrelates with lighting, object color affects specular reflection. In AutoCAD graphic system there is a big choice of materials, they can be edited or new one created [14].

Notwithstanding that 3D models are more accurate than 2D ones they don't look like natural, they are lack of real colors, shadows, lighting. Shading enables to generate accurate image of 3D scene based on different optical effects. On Figure 4, Figure 5 rendering scenes of aircraft "Chiroptera" shaded surfaces during cruising flight and target run are shown. 


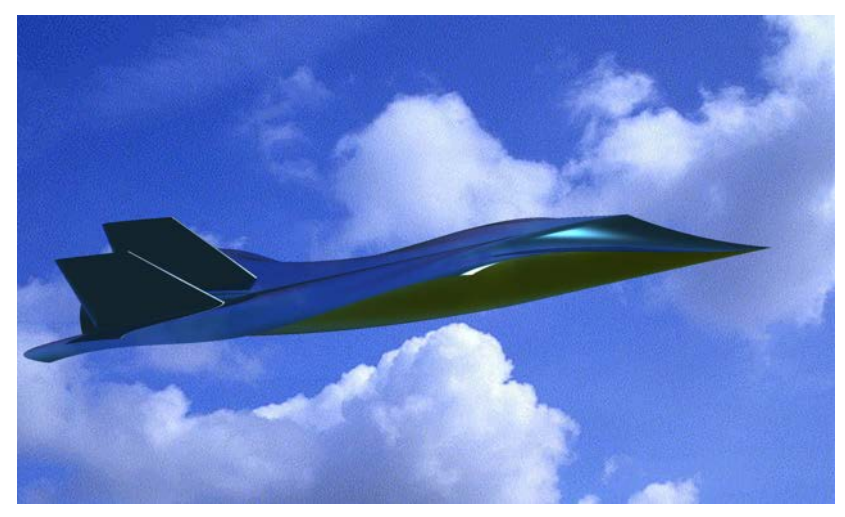

Figure 4. Rendering of "Chiroptera” aircraft conceptual model (cruising model)

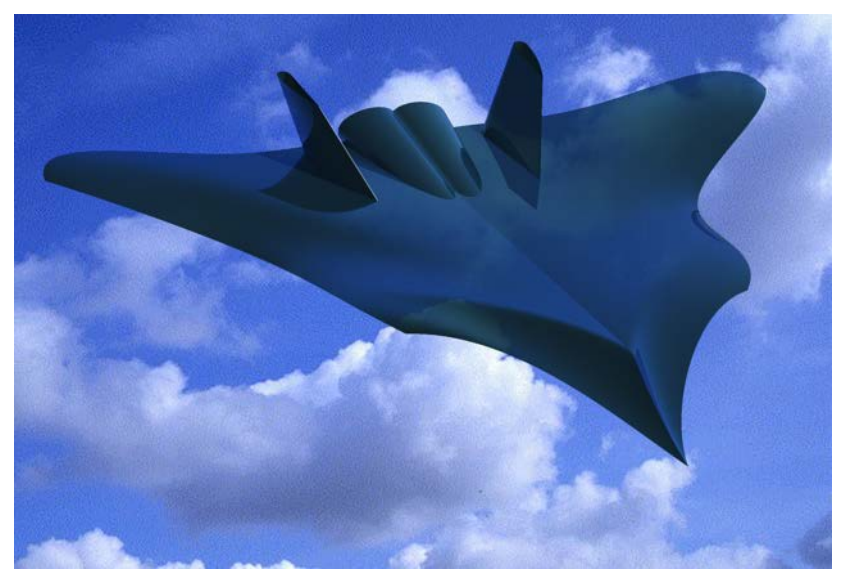

Figure 5. Rendering of “Chiroptera” aircraft conceptual model (target run)

\section{Conclusion}

In conclusion, it can be noted that in this paper the issues of new aircraft 3D modeling concept from creative sketches to accurate rendering were considered. The conceptual modeling of the new aircraft based on bionical forms has been developed. Design documentation can be also created in graphic system AutoCAD based on 3D model developed.

3D modeling of aircraft was carried out on the basis of well known methods. The given scenes of realistic rendering give visual presentation about future of industrial mechanical engineering product. Modern tools of computational modeling make designers possible to examine projects of future products in different variants till their real creation.

\section{References}

[1] Bolsunovsky A.L., Sonin O.V., et all. 2001. Flying wing problems and decision. Aircraft Design. 4 (4). 193-219.

[2] McMasters J.H. and Cummings R.M. 2002. Airplane Design Past, Present and Future. Journal of Aircraft. 39 (1), 10-17.

[3] Liebeck R. H. 2004. Design of the Blended Wing Body Subsonic Transport. Journal of Aircraft. 41 (1), 97-104.

[4] Saeed T.I., Graham W.R., Hall C.A. 2011. Boundary-layer suction system design for laminar-flying-wing aircraft. Journal of Aircraft. 48 (4), 1368-1379.

[5] Gavel H., Berry P., Axelsson A. 2006. Conceptual design of a new generation JAS 39 gripen aircraft. Collection of Technical Papers - 44th AIAA Aerospace Sciences Meeting. Reno. USA; 9-12 January 2006; (1). 395-406.

[6] Haimes R. and Drela M. 2012. On the construction of aircraft conceptual geometry for high-fidelity analysis and design. 50th AIAA Aerospace Sciences Meeting Including the New Horizons Forum and Aerospace Exposition 2012, Article numberAIAA 2012-0683. USA; 9-12 January 2012

[7] Website / Internet resource. - Mode of access www/URL:http://en.wikipedia.org/wiki/Chiroptera (date access 12.08.2013).

[8] Mosiyash S.S. 1985. A flying at night. Moscow: Znanie. 160p.

[9] Website / Internet resource. - Mode of access www/URL: http://airwar.ru/enc/law1/eole.html (date access 12.08.2013)

[10] Howe D. 2000. Aircraft Conceptual Design Synthesis. London: Professional Engineering Pub. Ltd. 474p.

[11] Jenkinson L.R., Marchman J.F. 2003. Aircraft design projects. Oxford.: Butterworth-Heinemann. 371p.

[12] Orekhov V.V., Abbasov I.B. 2013. Conceptual design of Amphibious. Proceedings of the Southern Federal University. Technical sciences. (1). 50-56.

[13] Abbasov I.B. and Orekhov V.V. 2012. Amphibious. Computational modeling. - Saarbrucken, Germany.: - LAP Lambert Academic Publishing, 69p. (www.lap-publishing.com)

[14] Abbasov I.B. 2011. Create drawings on the computer in AutoCAD 2012. Textbook. Moscow: DMK Press. 136p.

[15] Yeger S.M., Matvienko A.M., Shatalov I.A. 2003. Basics of aircraft: Textbook. M: Mashinostroenie, 720p.

[16] Raymer D.P. 2009. Living in the Future; The Education and Adventures of an Advanced Aircraft Designer, Design Dimension Press, Los Angeles, 360p. 